\title{
Stronger efferent suppression of cochlear neural potentials by contralateral acoustic stimulation in awake than in anesthetized chinchilla
}

\author{
Cristian Aedo ${ }^{1,2}$, Eduardo Tapia ${ }^{1,2}$, Elizabeth Pavez ${ }^{1,2}$, Diego Elgueda ${ }^{2+}$, Paul H. Delano ${ }^{2,3}$ and Luis Robles ${ }^{2 *}$ \\ 'Departamento de Tecnología Médica, Facultad de Medicina, Universidad de Chile, Santiago, Chile \\ ${ }^{2}$ Programa de Fisiología y Biofísica, ICBM, Facultad de Medicina, Universidad de Chile, Santiago, RM, Chile \\ ${ }^{3}$ Departamento de Otorrinolaringología, Hospital Clínico, Universidad de Chile, Santiago, Chile
}

\section{Edited by:}

Ana Elgoyhen, Instituto de

Investigaciones en Ingeniería

Genética y Biología Molecular,

Argentina

Reviewed by:

John J. Guinan, Massachusetts Eye

and Ear Infirmary and Harvard

Medical School, USA

Maria Eugenia Gomez-Casati,

Instituto de Investigaciones en Ingeniería Genética y Biología

Molecular, Argentina

\section{*Correspondence:}

Luis Robles, Programa de Fisiología

y Biofísica, ICBM, Facultad de

Medicina, Universidad de Chile,

Independencia 1027, Santiago, RM,

8380453, Chile

e-mail:Irobles@med.uchile.cl

${ }^{\dagger}$ Present address:

Diego Elgueda, Institute for Systems Research and

Neuroscience and Cognitive

Science Program, University of

Maryland, College Park, Maryland,

USA
There are two types of sensory cells in the mammalian cochlea, inner hair cells, which make synaptic contact with auditory-nerve afferent fibers, and outer hair cells that are innervated by crossed and uncrossed medial olivocochlear (MOC) efferent fibers. Contralateral acoustic stimulation activates the uncrossed efferent MOC fibers reducing cochlear neural responses, thus modifying the input to the central auditory system. The chinchilla, among all studied mammals, displays the lowest percentage of uncrossed MOC fibers raising questions about the strength and frequency distribution of the contralateralsound effect in this species. On the other hand, MOC effects on cochlear sensitivity have been mainly studied in anesthetized animals and since the MOC-neuron activity depends on the level of anesthesia, it is important to assess the influence of anesthesia in the strength of efferent effects. Seven adult chinchillas (Chinchilla laniger) were chronically implanted with round-window electrodes in both cochleae. We compared the effect of contralateral sound in awake and anesthetized condition. Compound action potentials (CAP) and cochlear microphonics (CM) were measured in the ipsilateral cochlea in response to tones in absence and presence of contralateral sound. Control measurements performed after middle-ear muscles section in one animal discarded any possible middleear reflex activation. Contralateral sound produced CAP amplitude reductions in all chinchillas, with suppression effects greater by about 1-3 dB in awake than in anesthetized animals. In contrast, $\mathrm{CM}$ amplitude increases of up to $1.9 \mathrm{~dB}$ were found in only three awake chinchillas. In both conditions the strongest efferent effects were produced by contralateral tones at frequencies equal or close to those of ipsilateral tones. Contralateral CAP suppressions for $1-6 \mathrm{kHz}$ ipsilateral tones corresponded to a span of uncrossed MOC fiber innervation reaching at least the central third of the chinchilla cochlea.

Keywords: olivocochlear, auditory efferent, contralateral MOC reflex, CAP suppression, frequency tuning, anesthesia

\section{INTRODUCTION}

The cochlea of mammals has two types of sensory cells: outer (OHC) and inner (IHC) hair cells. The IHCs make synaptic contact with the afferent fibers of the auditory nerve while the OHCs are fundamentally innervated by auditory efferent axons. The auditory efferent system originates in the auditory cortex and projects mainly through two pathways. One is directed to the medial geniculate body of the thalamus, wherein it makes synapses with the afferent fibers and returns to the cortex (Winer and Prieto, 2001). The other pathway descends to the inferior colliculus and superior olivary complex finally projecting through medial olivocochlear (MOC) fibers to both cochleae (Vetter et al., 1993). The MOC fibers are myelinated axons that originate in the ventral nucleus of the trapezoid body and that segregate into crossed and uncrossed fibers that make synaptic contact with OHCs in the contra- and ipsilateral cochleae, respectively. The lateral olivocochlear (LOC) system is constituted by unmyelinated neurons that project mainly to the ipsilateral cochlea making synaptic contacts beneath IHCs (Warr and Guinan, 1979). Based on the available experimental evidence several possible roles have been assigned to the auditory efferent system, such as: reduction of the masking effect produced by noise or tones (Kawase et al., 1993), a protective role in preventing loss of sensitivity caused by exposure to high-intensity sounds (Rajan, 1995), modulation of responses to auditory stimuli within the sleep-wake cycle (Velluti, 1997), modulation of cochlear sensitivity according to attentional processes (Delano et al., 2007) and a balancing effect on interaural sensitivity (Darrow et al., 2006). (For review see Guinan, 2006; Robles and Delano, 2008).

It has been shown that stimulation of the MOC efferent system by means of electrical pulses delivered at the floor 
of the fourth ventricle produces a decrease in the amplitude of auditory-nerve compound action potentials (CAP) and a concomitant increase in cochlear microphonic (CM) potentials (Galambos, 1956; Fex, 1959; Desmedt and Monaco, 1961; Gifford and Guinan, 1987; Elgueda et al., 2011). Auditory efferent fibers can also be activated by acoustic stimulation of the contralateral ear producing a decrease in single auditorynerve fiber and CAP responses to ipsilateral tones (Buño, 1978; Liberman, 1989; Warren and Liberman, 1989a). This efferent suppression produced by contralateral sounds, known as the "contra MOC reflex" (de Venecia et al., 2005) is mediated by MOC uncrossed fibers. In all species studied so far uncrossed MOC fibers comprise a smaller percentage of the total than the crossed MOC fibers (Robles and Delano, 2008). However, there are significant differences in the distribution of MOC fibers among species. The finding that the chinchilla displays the lowest percentage of uncrossed fibers among all studied mammals has raised questions about the strength and frequency distribution of the contra MOC reflex in this species (Iurato et al., 1978; Azeredo et al., 1999). In fact, as reported in Azeredo et al. (1999), the relative paucity of MOC uncrossed fibers and their strong apical bias may have been contributing factors in the early unsuccessful attempts to demonstrate CAP suppression with contralateral noise in the chinchilla.

The aims of this work are: to determine the strength of the contra MOC reflex at different locations along the cochlea in the chinchilla, to ascertain whether the suppression due to contralateral tones is tuned to the ipsilateral-tone frequency and to compare the CAP and CM efferent effects in the awake and anesthetized chinchilla.

\section{MATERIALS AND METHODS ANIMALS}

Seven adult Chinchillas (Chinchilla laniger) weighing between 400 and 700 grams were used. All procedures involving animals were made in accordance with NIH Guidelines for the Care and Use of Laboratory Animals, publication No. 86-23, revised 1996, and were approved by the Institutional Bioethics Committee (Comité de Bioética de Investigación en Animales, Facultad de Medicina, Universidad de Chile, permit number CBA \#0262). All surgeries were performed under ketamine and xylazine anesthesia, and every effort was made to minimize animal suffering.

\section{SURGERY}

Chinchillas were premedicated with atropine $(0.04 \mathrm{mg} / \mathrm{kg}$ I.M.), xylazine (3-8 mg/kg I.M.) and then anesthetized with ketamine (20-40 mg/kg, I.M.). After the surgery, they were treated with analgesics (Ketofen ${ }^{\circledR}, 3 \mathrm{mg} / \mathrm{kg}$ I.M.) and antibiotics (Baytril ${ }^{\circledR}$, $5 \mathrm{mg} / \mathrm{kg}$ I.M.) every $12 \mathrm{~h}$ for 5 days. A craniotomy was performed in the lateral tympanic bulla and a cochlear electrode (Nichrome ${ }^{\circledR}$ $200 \mu \mathrm{m}$ diameter) was placed on the round window niche membrane and connected to an external connector that was chronically implanted on the animal's skull. The middle-ear ossicles remained intact to preserve the physiologic conduction of sound to the cochlea. During surgery rectal temperature was maintained constant at $35-37^{\circ} \mathrm{C}$ by means of a heating pad. All surgical procedures were performed under a microscope (Zeiss ${ }^{\circledR}$, OpMi-1) with magnification of up to $40 \mathrm{x}$.

\section{STIMULATION PROTOCOL AND DATA ACQUISITION}

The effects produced by contralateral stimulation on cochlear potentials were measured in all chinchillas, first in awake and later in anesthetized condition. For the measurements in the awake condition the animals were kept in a custom-made motion restrainer that limited their movements with minimum discomfort in sessions of less than 45 min duration. The restrainer device consisted in a cloth hammock in which the animal was suspended and a padded ring that was adjusted around its neck to restrict the head movements. A week before the surgical electrode implantation, the animals were trained during 3-5 days in sessions not exceeding $45 \mathrm{~min}$ to stay quiet on the restrainer device.

All experiments were performed in a double-walled soundattenuating room, isolated from external noises and vibrations. The same stimulation protocol was used in anesthetized and awake animals. Acoustic stimuli were digitally generated with a National Instruments ${ }^{\circledR}$ (PCI-6071E) multifunction data acquisition device, attenuated by programmable attenuators (PA5, Tucker Davis Technologies ${ }^{\circledR}$, TDT System 3) and delivered through insertion phones (EC1 electrostatic speakers, TDT). Cochlear potentials were recorded in response to tones at different sound pressure levels (40-80 dB SPL for ipsilateral stimuli and 50-75 $\mathrm{dB}$ for contralateral stimuli) and frequencies ranging from $1-6 \mathrm{kHz}$. Acoustical stimuli were presented with alternated polarity in order to allow us to separate CAPs from CMs. Responses to stimuli of each polarity were independently averaged and later added together to cancel CMs and isolate CAP responses. Each stimulus sequence consisted of 3 consecutive series of 32 stimuli presented at a $1 \mathrm{~Hz}$ rate: control, efferent and recovery. In the control series the ipsilateral tones (15 ms duration) were presented alone. In the efferent series the ipsilateral tones (15 ms duration) were preceded by a contralateral tone or noise (500 ms duration) followed by a silent period ( $15 \mathrm{~ms}$ duration). In the recovery series the ipsilateral tones ( $15 \mathrm{~ms}$ duration) were again presented alone (Figure 1). The noise stimulus was digitally generated and filtered $(0.5-32 \mathrm{kHz})$ uniform white noise (LabWindows ${ }^{\circledR}$, white noise subroutine). Cochlear potentials were amplified $(10,000 \mathrm{X})$, filtered $(0.1-10 \mathrm{kHz})$ and digitized $\left(40,000\right.$ points/s) by a National Instruments ${ }^{\circledR}$ (PCI-6024E) card. CAP amplitudes were measured between the maximum and minimum of $\mathrm{N} 1$ and $\mathrm{P} 1$ waves (first and second peaks) of the average of 32 responses. Subtraction of the averaged responses to stimuli of the two polarities allowed the computation of the CM amplitudes by performing a Fast Fourier Transform (FFT) in a $12.8 \mathrm{~ms}$ window that excluded the CAP response. Efferent effects on CAP and CM responses were expressed in $\mathrm{dB}$ referred to the control amplitudes. In the case of efferent effects on CMs that were fairly small we used a threshold of $0.5 \mathrm{~dB}$ for $\mathrm{CM}$ amplitude changes. This threshold was established by measuring, in two animals, the variability of repeated measures of $\mathrm{CM}$ amplitude for the same parameters of ipsilateral stimulation, without efferent activation. The variability obtained ranged from 1 to $3 \%$ or 0.1 to $0.25 \mathrm{~dB}$, therefore to make sure the changes 


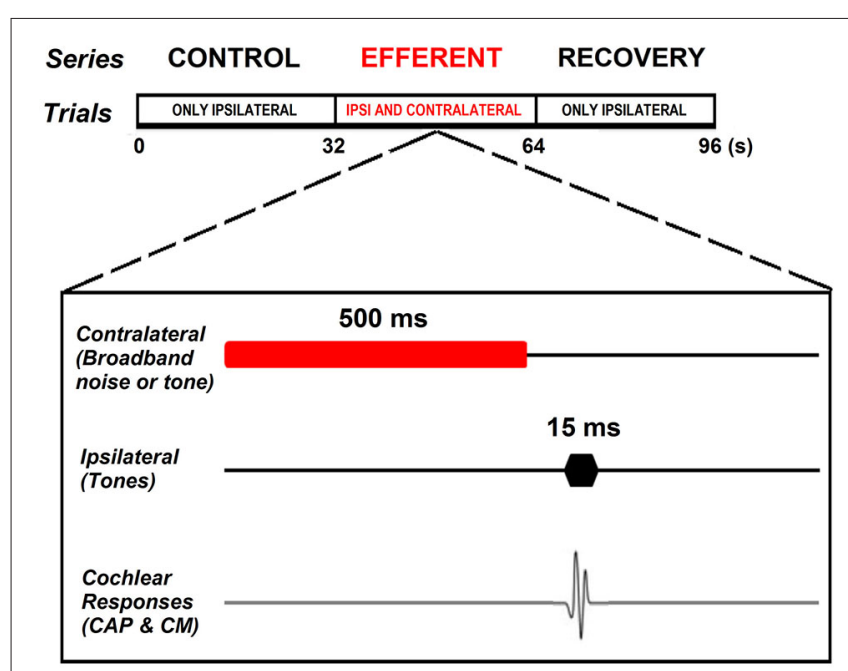

FIGURE 1 | Experimental paradigm. Each stimulation sequence consisted of three consecutive series of 32 stimuli presented at $1 \mathrm{~Hz}$ rate: control, efferent and recovery. Control series consisting of ipsilateral tones $115 \mathrm{~ms}$ duration) presented alone. Efferent series in which the ipsilateral tone (15 ms duration) was preceded by a contralateral tone or noise $(500 \mathrm{~ms}$ duration) followed by a silent period ( $15 \mathrm{~ms}$ duration). Recovery series in which the ipsilateral tones (15 ms duration) were again presented alone.

were not due to the variability of the responses we set a threshold equal twice the maximum variability. In two chinchillas at the end of the experiment we injected tetrodotoxin (TTX, 3 $\mu \mathrm{M})$, a powerful neurotoxin that blocks voltage-dependent $\mathrm{Na}^{+}$ ion channels, through the round window of the contralateral cochlea to block neural responses and repeated some of the measurements of contralateral-ear suppression. Data analysis was performed using custom-made C programs (LabWindows ${ }^{\circledR}$ ). The significance of the differences between the experimental and control series was checked using $t$-tests or ANOVA for normal distributed data or the Mann-Whitney test (SigmaPlot ${ }^{\circledR}$ v12.5) for non-normal data (as evaluated by the Shapiro-Wilk test).

\section{RESULTS}

The effect of contralateral broad-band noise on the magnitudes of the CAP and CMs generated in response to ipsilateral tones (1-6 kHz) was measured in seven chinchillas in awake and anesthetized condition. CAP-amplitude reductions produced by contralateral noise ranged from 1 to $7 \mathrm{~dB}$ in anesthetized and from 1 to $10 \mathrm{~dB}$ in awake animals. In contrast, no measurable contralateral-sound effects were obtained on CMs in anesthetized chinchillas. In awake state efferent effects on $\mathrm{CM}$ were found in only three chinchillas that displayed CM amplitude increases ranging from 0.5 to $1.9 \mathrm{~dB}$. Figure 2 depicts the effects of contralateral broad-band noise on CAP and CM responses obtained in the awake chinchilla that displayed the largest CM increases, concomitant to CAP reductions. Since contralateral-sound effects on CM potentials were obtained in only three awake animals the following description and analysis of results will be limited to the effects on CAP responses.
Figure 3 shows reductions produced by contralateral noise (40-50 dB SPL) in the amplitude of CAP responses to ipsilateral tones at four frequencies in one anesthetized chinchilla. In the figure green and red symbols indicate CAP amplitudes in absence and presence of contralateral stimulation, respectively. As exemplified in this figure, in all cases the presence of the contralateral sound produced an abrupt decrease in CAP amplitude that could be seen in the first CAP response after the onset of the contralateral stimulation series and an equally abrupt return to the control value at the offset of stimulation.

Figure 4 shows input-output curves of CAP amplitudes in response to ipsilateral tones at frequencies of 3 and $4 \mathrm{kHz}$ and intensities from 20 to $80 \mathrm{~dB}$ SPL obtained in absence and presence of contralateral broad-band noise (50 dB SPL; red curves) in one awake (blue) and anesthetized (green) chinchilla. All of the curves show a monotonic CAP amplitude increase with increasing stimulation intensity that in some cases reaches saturation at levels above $80 \mathrm{~dB}$ SPL (not shown). The figure compares CAP suppressions obtained at the two ipsilateral tone frequencies that displayed the strongest efferent effects. At both frequencies, in awake condition, all amplitude differences reached statistical significance for ipsilateral tones $<60 \mathrm{~dB}$ SPL, while in anesthetized condition, most amplitude differences were significant for ipsilateral tones $<50 \mathrm{~dB}$ SPL.

Contralateral stimulation with pure tones also produced CAP reductions in anesthetized as well as in awake animals; however, the magnitude of the effect was highly dependent on the frequency of the contralateral tone. Figure 5 displays examples of the reductions of CAP responses to ipsilateral tones at four frequencies $(2-6 \mathrm{kHz})$ produced by contralateral tones of different frequencies in awake and anesthetized animals. The efferent suppression produced by contralateral tones was always tuned to a frequency equal or close to the ipsilateral stimulus tone and, as in the case with contralateral noise, it was stronger in awake than in anesthetized animals. To give an idea of the differences in frequency tuning of efferent suppression observed in the different animals we present in Figure 6 the superposition of the curves of CAP reduction obtained, at four ipsilateral frequencies, for all contralateral frequencies tested in all animals in awake and anesthetized condition (intensity levels: 50-60 dB SPL ipsilateral and 60-70 dB SPL contralateral tones). Significant effects were obtained with frequency and with awake or anesthesia conditions as assessed by a two-way ANOVA (ipsilateral frequency vs. awake/anesthesia as factors): awake vs. anesthesia: $F_{(1)}=5.681, p=0.018$; ipsilateral frequency: $F_{(3)}=14.199, p<0.001$. However, there was no interaction between these factors: $F_{(3)}=0.182, p=0.908$. The magnitudes and extent of the CAP reductions were also dependent on the intensity of the contralateral tone. Figure 7 compares the magnitudes of CAP suppressions obtained in one animal, for a $4 \mathrm{kHz}$ ipsilateral tone in anesthetized and awake condition, with contralateral tones at frequencies ranging from 1800 to $6200 \mathrm{~Hz}$ and intensities at 58 and $68 \mathrm{~dB}$ SPL. In both conditions, awake and anesthetized, the efferent suppression effects were stronger and extended on a wider range of frequencies for the more intense contralateral tones. 


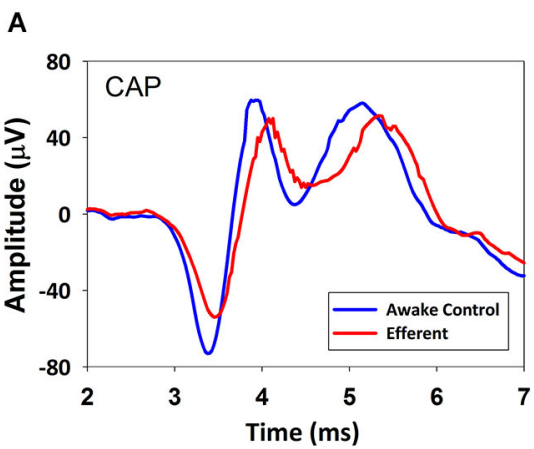

C

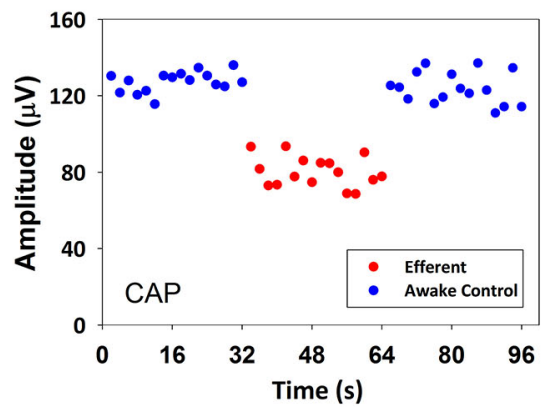

FIGURE 2 | CAP suppression and CM increase produced by contralateral acoustical stimulation in an awake chinchilla. (A) Average CAP traces of 32 responses to ipsilateral tones in absence (blue) and presence (red) of contralateral acoustical stimulation. (B) Average $\mathrm{CM}$ traces of 32 responses to ipsilateral tones in absence (blue) and presence (red) of contralateral acoustical stimulation. (C) CAP response amplitudes in repeated trials in absence (blue) and presence (red) of contralateral acoustical stimulation. Each symbol represents the average CAP amplitude ( $\mathrm{N} 1$ to $\mathrm{P} 1$ in $\mu \mathrm{V}$ ) of two consecutive trials. Significant CAP reductions were obtained with

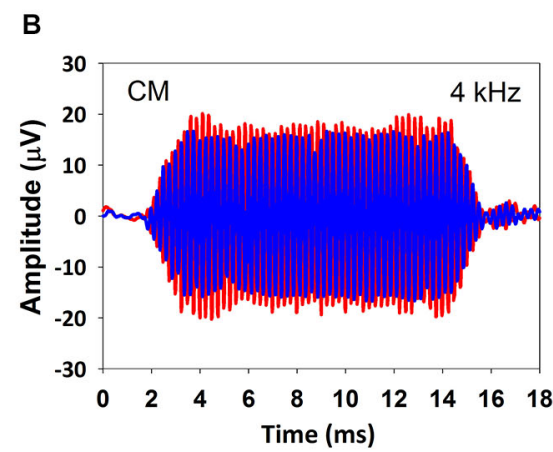

D

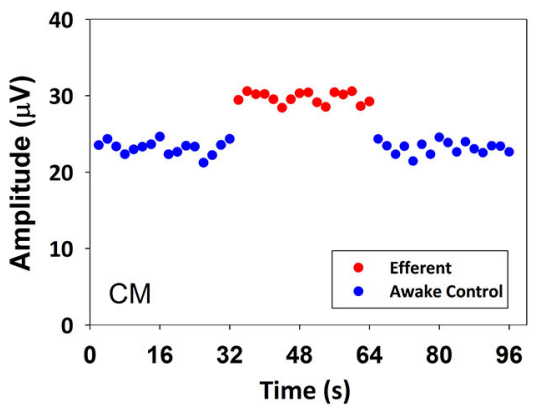

contralateral acoustical stimulation (two tailed $t$-test, $T_{(30)}=19.618$, $\left.p=1.157^{*} 10^{-18}\right)$. (D) CM response amplitudes in repeated trials in absence (blue) and presence (red) of contralateral acoustical stimulation. Each symbol represents the average $\mathrm{CM}$ amplitude of two consecutive trials. Amplitudes (rms in $\mu \mathrm{V}$ ) were obtained by fast Fourier transform (FFT). Significant CM enhancements were obtained with contralateral acoustical stimulation (two tailed $t$-test, $\left.T_{(30)}=-22.329, p=3.031^{*} 10^{-20}\right)$. In all panels ipsilateral tones were $4 \mathrm{kHz}$ at $60 \mathrm{~dB} \mathrm{SPL}$ and contralateral broad-band noise was at $55 \mathrm{~dB}$ SPL.
We have compared the CAP suppressions obtained in awake and anesthetized animals for $1-6 \mathrm{kHz}$ ipsilateral frequencies and similar stimulation intensity levels: 50-60 dB SPL ipsilateral tones and $60-70 \mathrm{~dB}$ SPL contralateral tones. Figure 8 depicts the maximum CAP reductions produced by contralateral stimulation, in each animal, at each ipsilateral frequency in awake and anesthetized condition (blue and green symbols, respectively). The figure also displays the average of the maximum CAP reductions produced by contralateral tones for all animals at each ipsilateral frequency in awake and anesthetized condition (blue and green dashed lines, respectively). As shown in the figure, the average CAP suppressions produced by contralateral tones in all chinchillas were significantly larger, at almost all frequencies, in the awake than in the anesthetized condition (Mann-Whitney test, $1 \mathrm{kHz}: U_{(7)}=6.0, T=71.0, p=0.017 ; 2 \mathrm{kHz}: U_{(7)}=0.0$, $T=77, p<0.001 ; 3 \mathrm{kHz}: U_{(7)}=7.5, T=69.5, p=0.026 ; 4 \mathrm{kHz}:$ $\left.U_{(5)}=2.0, T=38, p=0.032 ; 6 \mathrm{kHz}: U_{(3)}=3.0, T=12, p=0.7\right)$.

As mentioned above, the efferent CAP suppression produced by contralateral tones was always tuned in frequency; that is, there was a most effective contralateral frequency, close or equal to the ipsilateral-tone frequency, that produced maximal suppression (Figures 5-7). Figure 9 shows the relationship between the most effective contralateral frequencies and ipsilateral frequencies for all data obtained in awake and anesthetized animals (blue and green symbols, respectively). In both conditions, the most effective contralateral suppressor frequencies for ipsilateral frequencies $<4 \mathrm{kHz}$ were nearly equal to the ipsilateral frecuencies, while for ipsilateral frequencies $\geq 4 \mathrm{kHz}$ they were consistently lower than ipsilateral frequencies, as shown by the average values of the most effective contralateral frequencies (dashed lines). This different relation between most effective contralateral and ipsilateral frequencies is also illustrated in Figure 10, which depicts CAP suppressions as a function of the difference (in octaves) between most effective suppressor and ipsilateral frequencies for the data obtained in all animals, but segregated into two groups according to the values of ipsilateral frequency. In awake, as well as, in anesthetized animals CAP suppressions display distributions that, for ipsilateral frequencies $<4 \mathrm{kHz}$ are centered at most effective suppressor frequencies equal to ipsilateral frequencies, while for ipsilateral frequencies $\geq 4 \mathrm{kHz}$ exhibit an offset of -0.26 octaves between most effective suppressor and ipsilateral frequencies. The figure shows that CAPsuppression curves for ipsilateral frequencies $\geq 4 \mathrm{kHz}$ display higher tuning than those of ipsilateral frequencies $<4 \mathrm{kHz}$, but that there are no changes in the pattern of tuning with and without anesthesia. 


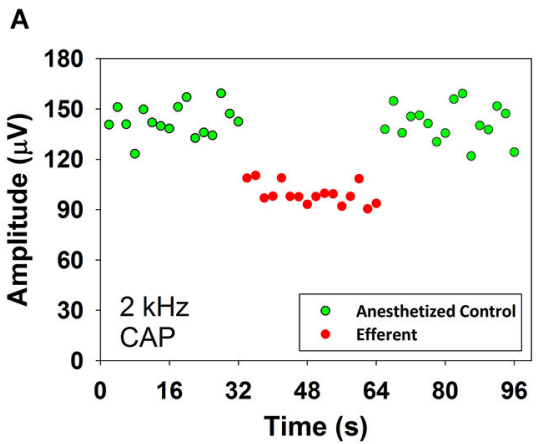

C

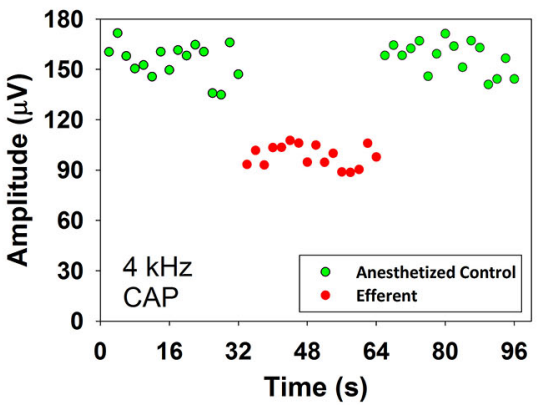

FIGURE 3 | CAP suppression produced by contralateral acoustical stimulation in an anesthetized chinchilla. Reductions of CAP amplitudes in response to ipsilateral tones obtained in the presence of contralateral broad-band noise ( $55 \mathrm{~dB}$ SPL). Each symbol represents the average CAP amplitude of two consecutive trials. The red circles correspond to responses to ipsilateral tones preceded by contralateral efferent stimulation. The green circles correspond to responses to ipsilateral tones alone, before and after

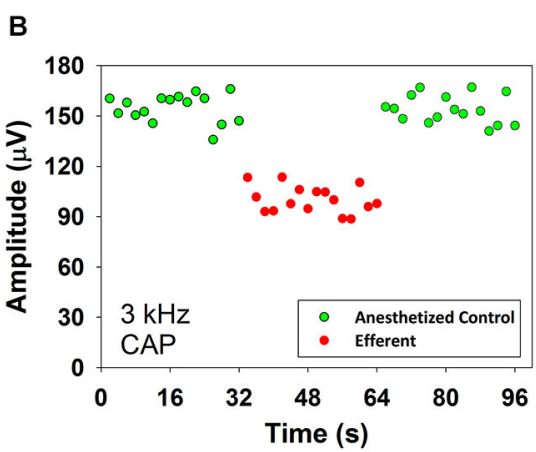

D

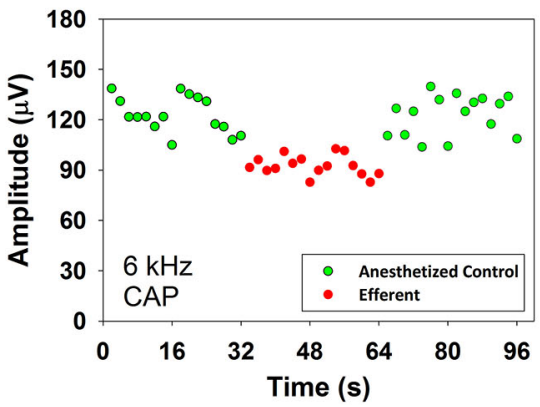

contralateral efferent stimulation. Panel (A): $2 \mathrm{kHz}$ at $47 \mathrm{~dB}$ SPL, panel (B): $3 \mathrm{kHz}$ at $50 \mathrm{~dB}$ SPL, panel (C): $4 \mathrm{kHz}$ at $44 \mathrm{~dB}$ SPL and panel (D): $6 \mathrm{kHz}$ at $40 \mathrm{~dB}$ SPL. Significant CAP reductions were obtained with contralateral acoustical stimulation at $2 \mathrm{kHz}$ (two tailed $t$-test, $T_{(30)}=15.324$, $\left.p=9.919 * 10^{-16}\right), 3 \mathrm{kHz}$ (two tailed $t$-test, $T_{(30)}=18.924, p=3.150 * 10^{-18}$ ), $4 \mathrm{kHz}$ (two tailed $t$-test, $T_{(30)}=9.920, p=5.509 * 10^{-11}$ ) and $6 \mathrm{kHz}$ (two tailed t-test, $\left.T_{(30)}=18.391, p=6.957^{*} 10^{-18}\right)$.
In order to discard any possibility that the reduction in CAP amplitude could be produced by activation of the middle-ear reflex, in one anesthetized animal the experimental protocol for frequency tuning of CAP suppression was repeated after section of the tensor tympani muscle and detachment of the stapedius muscle from its insertion. As shown in Figure 11, at four ipsilateral frequencies, no significant differences were found in contralateral CAP suppression for the magnitudes obtained before and after the middle-ear muscle section.

In addition, we performed two kinds of controls to show that CAP suppression was mediated by MOC neurons activated from the contralateral ear and was not due to ipsilateral forward masking or ipsilateral activation of MOC fibers produced by crosstalk of contralateral stimuli to the ipsilateral ear. First, in two animals we injected tetrodotoxin (TTX), a powerful neurotoxin blocker of voltage-dependent $\mathrm{Na}^{+}$ ion channels, into the contralateral cochlea. After minutes of the TTX injection, in both animals, the toxin abolished the contralateral-ear neural responses and also their suppressive effect on ipsilateral CAPs (Figure 12). The disappearance of the CAP suppression after the TTX contralateral injection showed that the effect was mediated by the neural response of the contralateral ear. Second, in one chinchilla we determined that the interaural attenuation was higher than $40 \mathrm{~dB}$ at all frequencies of contralateral stimulation. Then, after measuring the CAP suppression produced by a contralateral tone, we evaluated the CAP suppression produced by an ipsilateral tone at an intensity $40 \mathrm{~dB}$ lower than that of the contralateral tone. CAP suppression was found for the contralateral tone stimulation, but not for the $40 \mathrm{~dB}$-lower ipsilateral tone, thus showing that the CAP suppression measured in the experiments was exclusively produced by MOC neurons activated from the contralateral ear.

\section{DISCUSSION}

The effect of contralateral sound stimulation on cochlear responses has been studied recording auditory-nerve fiber and CAP responses and distortion product otoacoustic emissions (DPOAEs) in cat, guinea pig and mice (Buño, 1978; Liberman, 1989; Warren and Liberman, 1989a,b; Puel and Rebillard, 1990; Popelár et al., 2001; Boyev et al., 2002; Chambers et al., 2012). In the cat it has been shown that contralateral tones and broad-band noise produce a decrease in the responses of single auditory-nerve fibers to ipsilateral tones that is greatest for auditory fibers with CF near $2 \mathrm{kHz}$ and that could reach up to about 70\% (Warren and Liberman, 1989a). Severing of the olivocochlear bundle at the internal auditory meatus completely eliminated the suppressive effects of contralateral sound, while severing only the crossed olivocochlear fibers did not eliminate them, thus indicating that these contralateral-sound suppressive effects were mediated by 

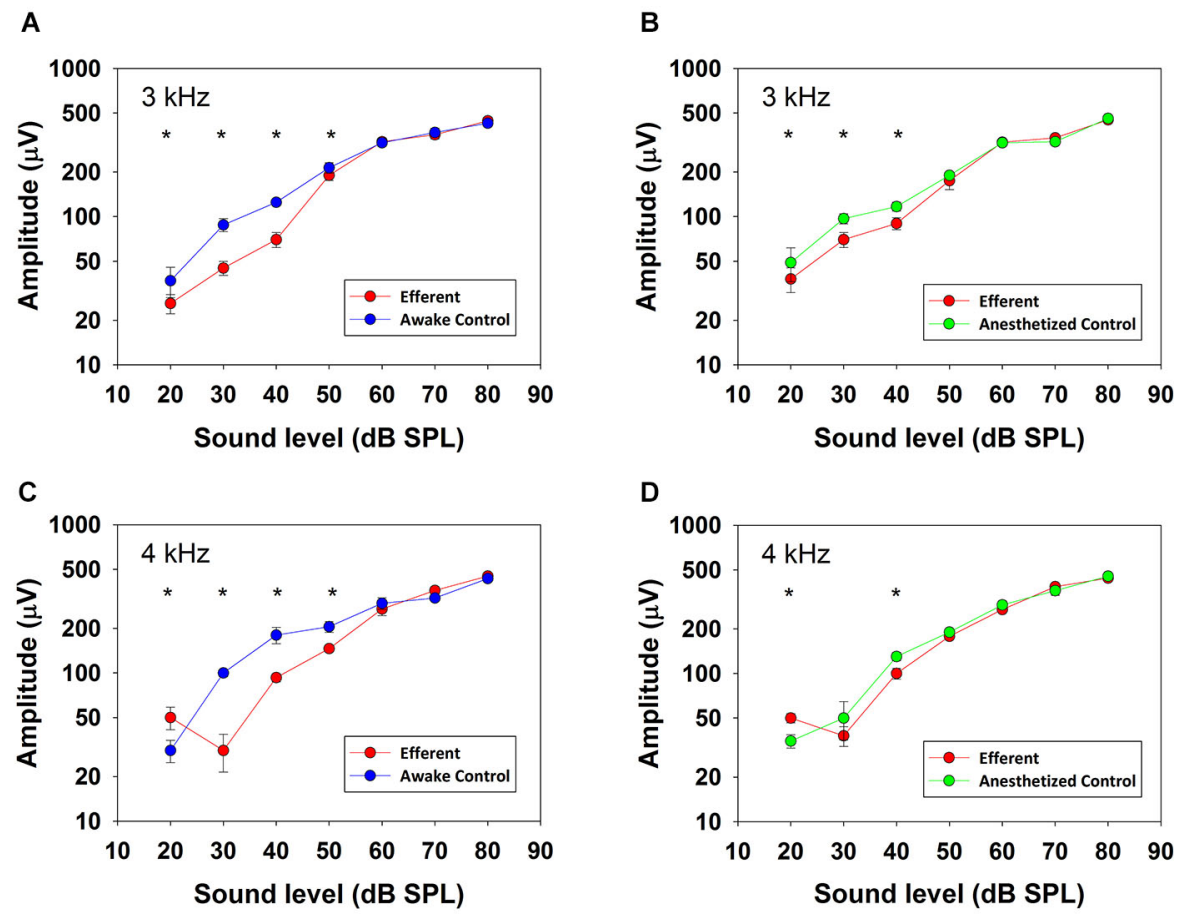

FIGURE 4 | CAP input-output curves. CAP amplitudes obtained in one chinchilla without (blue and green) and with (red) contralateral acoustical stimulation (broad-band noise at $50 \mathrm{~dB}$ SPL) in awake (blue) and anesthetized (green) condition. Vertical lines indicate standard deviations.

Efferent-activation produced by contralateral stimulation is more effective at low ipsilateral stimulus intensities and efferent reductions are higher in awake than in anesthetized animals. Asterisks indicate statistically significant differences. Panel (A): 3 kHz, 20 dB: (Mann-Whitney, $U_{(32)}=30.0, T=1522$, $p<0.001$ ); $3 \mathrm{kHz}, 30 \mathrm{~dB}$ : (Mann-Whitney, $U_{(32)}=0.0, T=528.0, p<0.001$ ); $3 \mathrm{kHz}, 40 \mathrm{~dB}$ : (Mann-Whitney, $U_{(32)}=0.0, T=1522.0, p<0.001$ ); $3 \mathrm{kHz}$,

50 dB: (Mann-Whitney, $\left.U_{(32)}=126.0, T=1426.0, p<0.001\right)$. Panel (B): $3 \mathrm{kHz}, 20 \mathrm{~dB}$ : (Mann-Whitney, $U_{(32)}=170.0, T=1382.0, p<0.001$ ); $3 \mathrm{kHz}, 30 \mathrm{~dB}$ : (Mann-Whitney, $U_{(32)}=5.0, T=1547.0, p<0.001$ ); $3 \mathrm{kHz}$, $40 \mathrm{~dB}$ : (Mann-Whitney, $\left.U_{(32)}=0.0, T=528.0, p<0.001\right)$. Panel (C): $4 \mathrm{kHz}$, $20 \mathrm{~dB}$ : (Mann-Whitney, $\left.U_{(32)}=266.0, T=1286.0, p<0.001\right) ; 4 \mathrm{kHz}, 30 \mathrm{~dB}$ : (Mann-Whitney, $U_{(32)}=0.0, T=528.0, p<0.001$ ); $4 \mathrm{kHz}, 40 \mathrm{~dB}$ : (Mann-Whitney, $U_{(32)}=0.0, T=528.0, p<0.001$ ); $4 \mathrm{kHz}, 50 \mathrm{~dB}$ : (Mann-Whitney, $U_{(32)}=179.0, T=707.0, p<0.001$ ). Panel (D): 4 kHz, $20 \mathrm{~dB}$ : (Mann-Whitney, $U_{(32)}=266.0, T=1286.0, p<0.001$ ); $4 \mathrm{kHz}, 40 \mathrm{~dB}$ : (Mann-Whitney, $U_{(32)}=2.0, T=1550.0, p<0.001$ ). uncrossed olivocochlear fibers (Warren and Liberman, 1989a). Suppressive effects of contralateral noise and tones on CAP responses have also been reported in anesthetized cats and guinea pigs (Liberman, 1989; Puria et al., 1996; Larsen and Liberman, 2009). These suppressive effects, as in the case of auditorynerve responses, were mediated by uncrossed olivocochlear fibers. Furthermore, Liberman (1989) recording CAP and single olivocochlear-fiber responses in the same animals obtained good correlation between the strength of CAP suppression and the sound-evoked discharge rates of single olivocochlear neurons. All of this evidence indicates that the effects of contralateral sound stimulation are dependent on the uncrossed MOC efferent fibers.

As mentioned in the Introduction, among all species studied, the chinchilla is the one that presents the lowest percentage of uncrossed MOC fibers (about 20\%; Azeredo et al., 1999). Since these are the efferent fibers comprising the neural pathway that mediates contralateral sound suppression, their scarcity in the chinchilla raised doubts about the strength and frequency distribution of the contralateral-sound suppression that could be found in this species. In fact, early works in chinchilla reported unsuccessful attempts to suppress CAP responses and
DPOAEs with contralateral noise stimulation (Azeredo et al., 1999). In contrast with the outcome of those early attempts, more recent studies in chinchilla have succeed in finding contralateral-sound suppressive effects on ipsilateral DPOAEs (James et al., 2005; Harrison et al., 2008; Wolter et al., 2014) and in the present work we are reporting consistent contralateralsound suppression of CAP responses in the seven chinchillas studied.

\section{EFFERENT MODULATION OF COCHLEAR RESPONSES IN CHINCHILLA}

Two types of efferent effects on cochlear responses with different temporal courses have been described: fast effects that have time constants of tens of milliseconds and slow effects that have time constants three orders of magnitude larger (Sridhar et al., 1995; Cooper and Guinan, 2003). Although our experimental paradigm allowed the assessment of both fast and slow MOC effects, we only found fast amplitude changes in cochlear potentials. In all animals CAP amplitudes abruptly decreased at the onset of the contralateral stimulation series and abruptly returned to control values at the offset, without evidence of slower changes of amplitude during the 32 s stimulation period. Similar abrupt amplitude increases, 


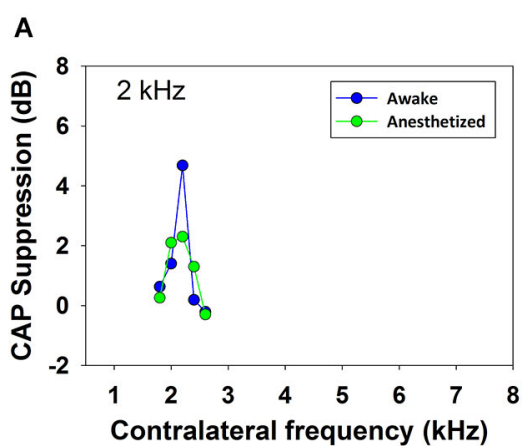

C

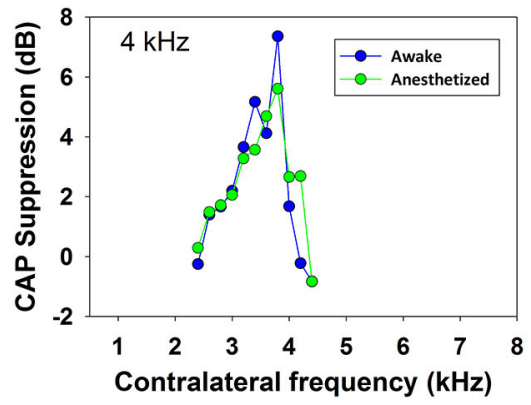

FIGURE 5 | Frequency tuning of ipsilateral CAP reduction produced by contralateral tone stimulation. Efferent reduction of CAP amplitudes produced by the presence of contralateral acoustical stimulation in four animals, in awake (blue) and anesthetized (green) condition, for ipsilateral

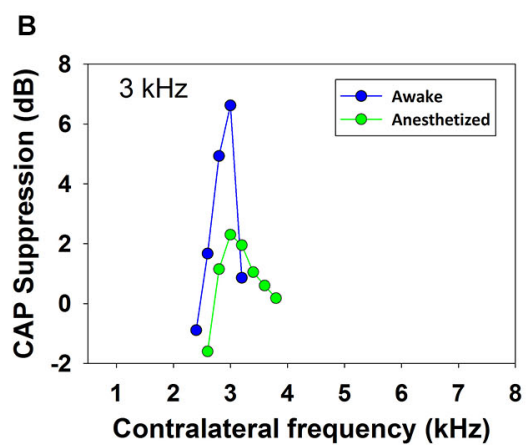

D

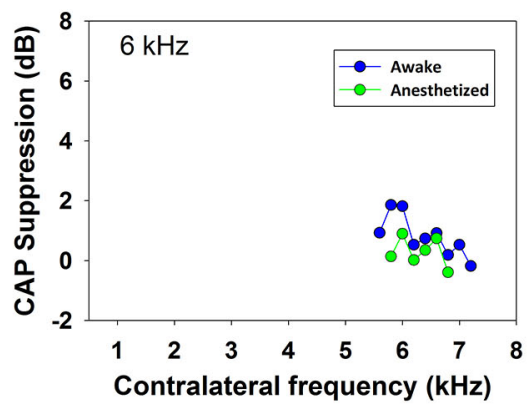

tones at frequencies of 2, 3, 4 and $6 \mathrm{kHz}$. Intensities of the ipsilateral and contralateral tones were, panel (A): 55 and $69 \mathrm{~dB} \mathrm{SPL}$, panel (B): 58 and $64 \mathrm{~dB}$ SPL, panel (C): 56 and $62 \mathrm{~dB}$ SPL and panel (D): 53 and 58 dB SPL. instead of decreases, were observed in the CM responses of the three awake chinchillas that exhibited CM efferent effects (see Figures 2, 3). However, it is possible that our contralateral stimulation period could have been too short to produce slow effects, as other studies using other contralateral stimulation paradigms in chinchilla have reported slow efferent effects after $1 \mathrm{~min}$ of contralateral stimulation (Bowen et al., 2014)

We have found in chinchilla large CAP-amplitude suppressions produced by contralateral broad-band noise as well as by contralateral tones. But, a comparison of the magnitudes of contralateral CAP suppression obtained in our study in chinchilla with values reported in other species is difficult because of the dependance of suppression on the different paradigms and parameters of stimulation used by different authors. However, in spite of the lower percentage of uncrossed MOC fibers in chinchilla, our highest values of suppression of about $10 \mathrm{~dB}$ (computed as equivalent or effective attenuation; Desmedt, 1962; Liberman, 1989) are similar to those reported in cat (Liberman, 1989).

We were able to demonstrate contralateral CAP suppression for ipsilateral tones with frequencies in the range of $1-6 \mathrm{kHz}$. This would indicate a span of efferent innervation reaching at least the central third of the cochlea, according to the chinchilla cochlea frequency-position map (Müller et al., 2010). The only anatomical study on efferent fiber distribution available in chinchilla shows that uncrossed MOC fibers have a strong bias toward the more apical cochlear regions: no uncrossed MOC fibers were found in the most basal cochlear region, only $12 \%$ of MOC fibers in the basal turn, about 30\% in the second turn and $57 \%$ in the apical turn (Iurato et al., 1978). This anatomical distribution of uncrossed MOC fibers is compatible with our finding of contralateral suppression for ipsilateral tones with frequencies of 1-6 kHz. The largest suppressions produced by contralateral tones in this study were for ipsilateral frequencies at 3 and $4 \mathrm{kHz}$. In the cat the largest CAP suppressions were found for an ipsilateral frequency of $1.5 \mathrm{kHz}$ (Liberman, 1989). In both cases maximal suppressions occurred for frequencies corresponding to locations in the mid turn of the cochlea (Greenwood, 1990; Müller et al., 2010).

As mentioned in Results, we consistently found that contralateral sounds produced substantial CAP-amplitude reductions and no measurable effects on CMs in anesthetized chinchillas and small CM enhancements in only three of the seven awake chinchillas. This absence or weakness of efferent effects on CMs in the present results is consistent with results obtained in a previous study in which we electrically stimulated MOC fibers in chinchilla and obtained significant CAP reductions of up to $11 \mathrm{~dB}$ (for $2 \mathrm{kHz}$ tones) accompanied by much smaller CM increases of $<2.5 \mathrm{~dB}$ (Elgueda et al., 2011). The lesser efferent effects on CMs than on CAPs have also being reported for sustained contralateral noise that elicits sizable CAP suppressions and 


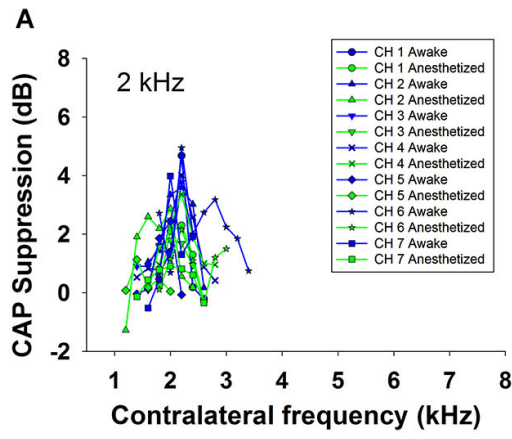

C

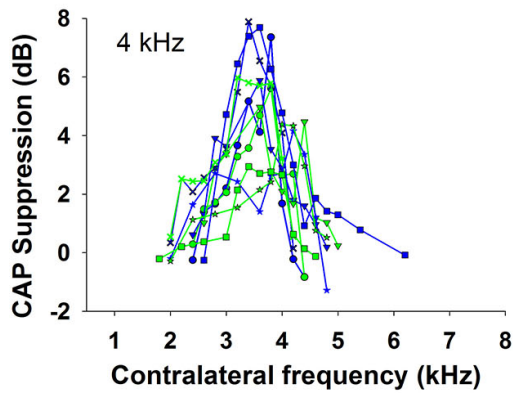

FIGURE 6 | Frequency tuning of ipsilateral CAP reduction produced by contralateral tone stimulation in all animals. Superposition of the curves of CAP suppression produced by contralateral acoustical stimulation in all animals, in awake (blue) and anesthetized (green)
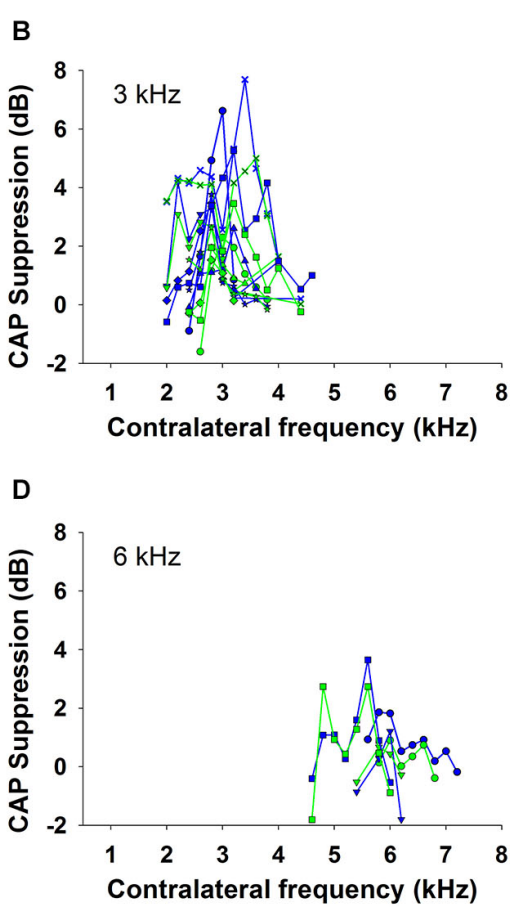

condition, for ipsilateral tones at, panel (A): $2 \mathrm{kHz}$, panel (B): $3 \mathrm{kHz}$, panel (C): $4 \mathrm{kHz}$ and panel (D): $6 \mathrm{kHz}$. Intensities of the tones were: 50 to $60 \mathrm{~dB}$ SPL for the ipsilateral and 60 to $70 \mathrm{~dB}$ SPL for the contralateral tones. only small CM enhancements (Larsen and Liberman, 2009). In contrast, auditory cortex deactivation in chinchilla, in most cases, produced decreases in both CM and CAP responses (León et al., 2012). In that case, as mentioned by the authors, the effects may have involved not only the activity of medial, but also lateral OC efferent fibers.

\section{COMPARISON OF SUPPRESSION IN ANESTHETIZED AND AWAKE ANIMALS}

Contralateral-sound suppression of cochlear responses has been mostly studied in anesthetized animals and it is known that the activity of medial OC neurons is dependent on the level of anesthesia (Liberman and Brown, 1986). Accordingly, to assess the physiological importance of this suppression effect it is important to measure it in awake animals. A study that compared contralateral-sound suppression of DPOAEs in anesthetized and awake guinea pigs found that suppression was much weaker in urethane-anesthetized than in awake animals, and that it was even weaker in pentobarbitone-anesthetized animals (Guitton et al., 2004). In this study we have compared the contralateral suppression of CAP responses in anesthetized and awake chinchillas finding that the mean values of suppression were higher by $1-3 \mathrm{~dB}$ in the awake than in the anesthetized condition (see Figure 8). These results add to previous evidence (Boyev et al., 2002; Guitton et al., 2004; Chambers et al., 2012) showing that when comparing the strength of efferent suppression measured in awake human subjects with that in experimental animals one must keep in mind that the latter is mostly measured in anesthetized animals and, consequently, is consistently underestimated.

\section{FREQUENCY TUNING OF CONTRALATERAL SUPPRESSION}

In all chinchillas, in anesthetized and awake condition, we found that the contralateral-tone CAP suppression was frequency tuned; that is, suppression had a peak for contralateral tones at frequencies equal or near those of the ipsilateral tones and decreased at a fast-rate for higher and lower frequencies (Figures 5-7). This tuning of contralateral suppression indicates a correspondence between the tonotopic distribution of afferent and efferent cochlear neural fibers. Afferent fibers from a contralateral cochlear location with a certain characteristic frequency activate MOC efferent neurons that innervate ipsilateral cochlear locations having similar characteristic frequencies. The close correspondence that we have found between the most effective contralateral frequencies and ipsilateral frequencies (Figure 9) is similar to that reported for auditory-nerve responses in cat (Warren and Liberman, 1989b). However, in the cat the most effective contralateral frequencies displayed a slight deviation from ipsilateral frequencies for ipsilateral tones at frequencies less than $3 \mathrm{kHz}$ while in our case the deviation was for ipsilateral frequencies $\geq 4 \mathrm{kHz}$. These results are also in agreement with anatomical data of single olivocochlear neurons in cat and guinea pig showing that the cochlear region innervated by an efferent neuron corresponds 


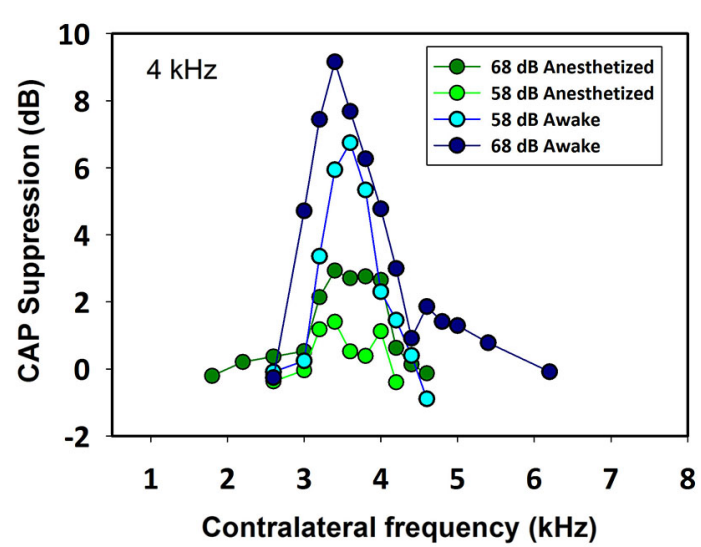

FIGURE 7 | Frequency tuning curves of ipsilateral CAP reduction produced by contralateral tones at two intensities in an awake and anesthetized chinchilla. The magnitude and extent of the CAP reduction depend on the contralateral stimulus frequency and intensity. In this case, for a $4 \mathrm{kHz}$ ipsilateral tone (48 $\mathrm{dB}$ SPL) the greatest CAP reductions were obtained for contralateral frequencies between 3400 and $4000 \mathrm{~Hz}$. As in all other animals, the efferent effect was better tuned and stronger in awake than in anesthetized condition. Awake vs. anesthetized, $68 \mathrm{~dB}$ SPL

(Mann-Whitney, $U_{(32)}=0.0, T=392, p<0.001$ ), $58 \mathrm{~dB}$ SPL

(Mann-Whitney, $U_{(32)}=0.0, T=392, p<0.001$ ); $68 \mathrm{~dB}$ SPL vs. $58 \mathrm{~dB}$ SPL, awake (Mann-Whitney, $U_{(32)}=45.0, T=181, p=0.002$ ), anesthetized (Mann-Whitney, $U_{(32)}=0.0, T=136, p<0.001$ ).

(or is close) to the place innervated by afferent neurons with the same characteristic frequency (Robertson and Gummer, 1985; Liberman and Brown, 1986). The widths of the frequency tuning curves for CAP suppression that we obtained in chinchilla would correspond to efferent innervation spans of about 4 to $8 \%$ of total cochlear length; these values are in between those obtained by fiber labeling in cat $(2.2-11.2 \%)$ by Liberman and Brown (1986) and in guinea pig $(<1-2 \%$ and $1.4-7.8 \%)$ by Robertson

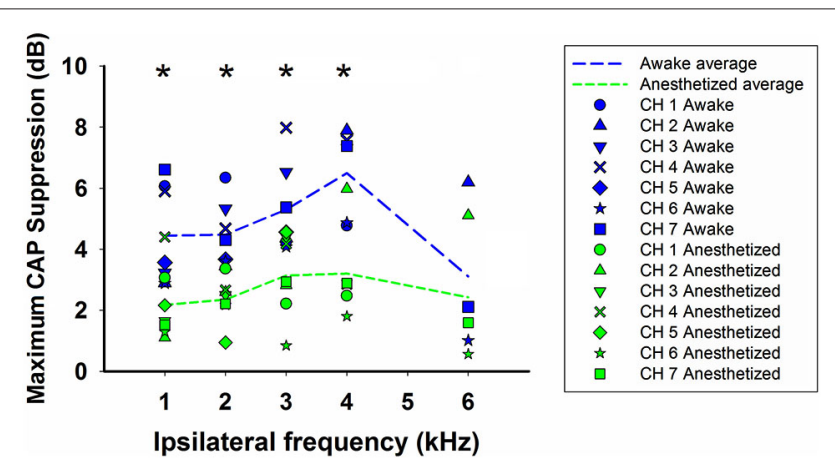

FIGURE 8 | Summary of efferent CAP suppression in awake and anesthetized animals. Symbols depict maximum CAP supressions produced by contralateral stimulation, in each animal, at each ipsilateral frequency in awake (blue) and anesthetized (green) condition. The dashed lines display the average of the maximum CAP reductions produced by contralateral tones for all animals at each ipsilateral frequency in awake (blue) and anesthetized condition (green). Intensities of ipsilateral and contralateral tones were 50-60 and 60-70 dB SPL, respectively. Asterisks indicate statistical significance.

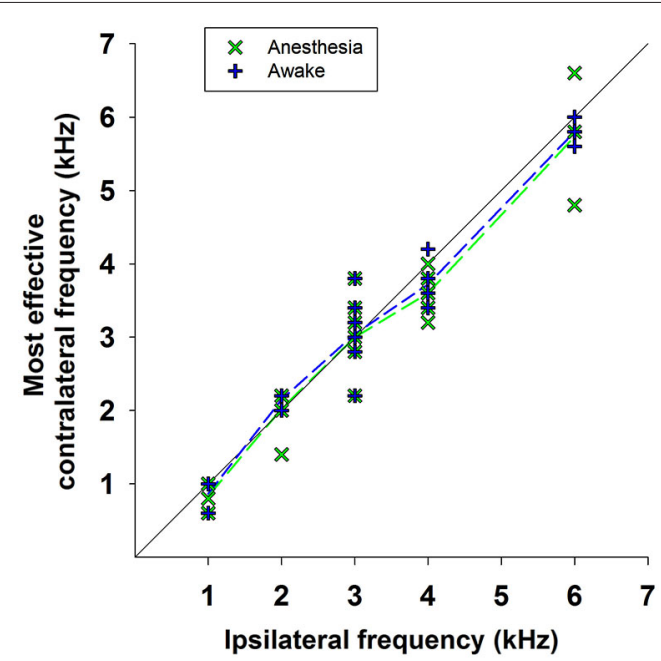

FIGURE 9 | Most effective contralateral suppressor frequencies vs. ipsilateral frequencies. Relationship between the frequencies of the most effective contralateral suppressors and the ipsilateral tones for all data obtained in awake (blue symbols) and anesthetized (green symbols) animals. The dashed lines indicate the average values of the most effective contralateral suppressors frequencies for all measurements at each ipsilateral frequency in awake (blue dashed line) and anesthetized (green dashed line) animals.

(1984) and Robertson and Gummer (1985), and Brown (1987), respectively.

Our finding of narrow frequency tuning curves for contralateral CAP suppression, although in good agreement with suppression tuning curves previously obtained for auditorynerve and CAP responses in anesthetized cats (Liberman, 1989; Warren and Liberman, 1989b), are in contradiction with two completely different frequency-selectivity characteristics of suppression recently reported using OAEs in humans. Stimulus frequency OAE measurements in humans indicate that the strength of contralateral suppression depends on the integration of the effect from almost the entire length of the contralateral cochlea (Lilaonitkul and Guinan, 2009). On the other hand, spontaneous OAE measurements indicate that contralateral suppression is tuned to a fixed narrow frequency band, between 500 and $1,000 \mathrm{~Hz}$, independent of the spontaneous OAE frequency (Zhao and Dhar, 2012). As mentioned above, the narrow tuning of MOC effects that we have observed agrees well with previous evidence on cochlear efferent innervation, while the results obtained using different types of OAEs to assess MOC-effect tuning in humans are contradictory and difficult to interpret.

\section{CONTROLS TO DISCARD ANY MIDDLE-EAR INVOLVEMENT IN SUPPRESSIVE EFFECTS}

As mentioned above, there is solid experimental evidence indicating that the suppressive effects of contralateral sounds on cochlear responses are mediated by efferent uncrossed MOC fibers (Warren and Liberman, 1989a). However, there is always a possibility, especially when using high levels of stimulation, that the suppressive effects on CAP responses could be partially 

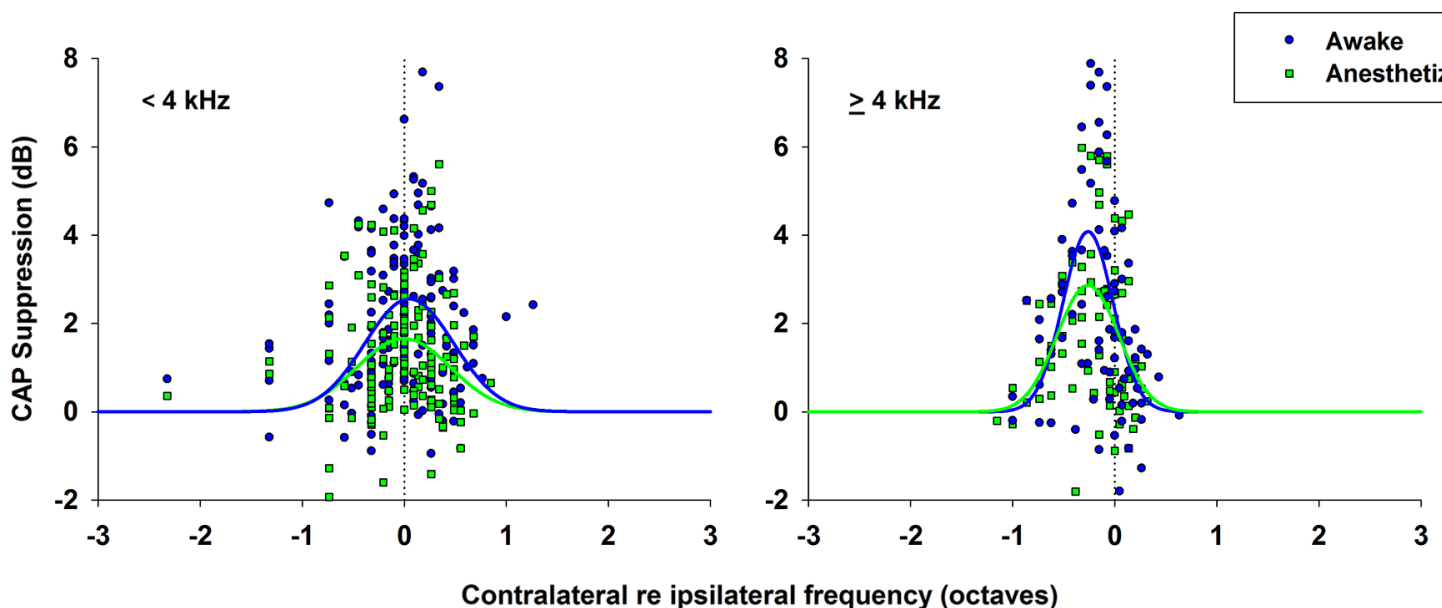

Contralateral re ipsilateral frequency (octaves)

FIGURE 10 | CAP suppression as a function of contralateral suppressor frequency re ipsilateral frequency. CAP suppressions as a function of the difference between contralateral frequencies and ipsilateral frequencies (in octaves) for all data in awake (blue circles) and anesthetized (green squares) animals. Normal distributions fitted to data, awake (blue line), anesthetized (green line). (Left) CAP suppression for ipsilateral frequencies $<4 \mathrm{kHz}$. Awake, $f(x)=2.56 e^{-0.5}\left(\frac{x-0.0483}{0.435}\right)^{2} ;$ anesthetized, $f(x)=1.66 e^{-0.5}\left(\frac{x+0.0067}{0.435}\right)^{2}$. (Right) CAP suppression for ipsilateral frequencies $\geq 4 \mathrm{kHz}$. Awake, $f(x)=4.084 e^{-0.5}\left(\frac{x+0.262}{0.245}\right)^{2} ;$ anesthetized, $f(x)=2.868$ $e^{-0.5}\left(\frac{x+0.263}{0.301}\right)^{2}$

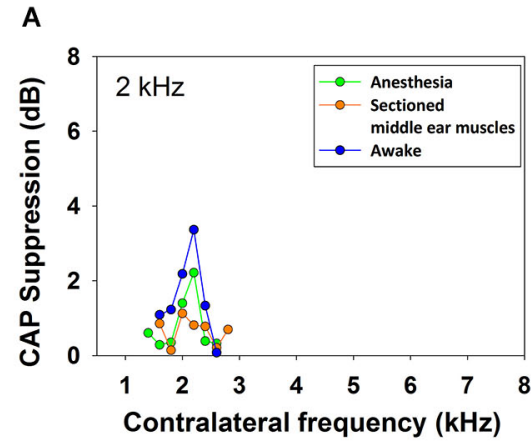

C

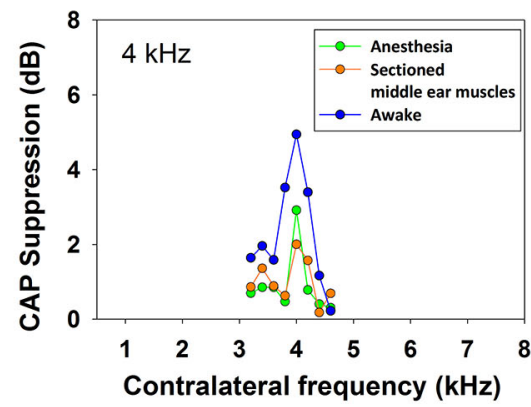

FIGURE 11 | Frequency tuning curves in awake and anesthetized chinchilla with intact and sectioned middle-ear muscles. Efferent reduction of CAP amplitudes produced by contralateral acoustical stimulation (70 dB SPL) in one animal, awake (blue), anesthetized (green) and anesthetized with detached middle-ear muscles (orange),

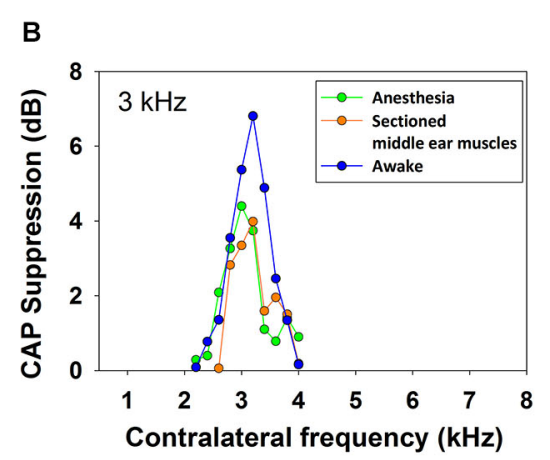

D

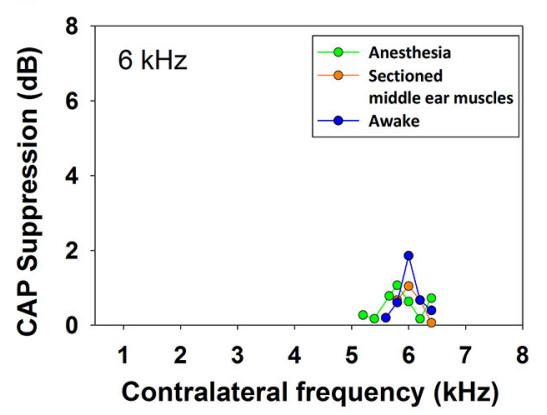

for ipsilateral tones (50 dB SPL) at, panel (A): $2 \mathrm{kHz}$, panel (B) $3 \mathrm{kHz}$, panel (C): $4 \mathrm{kHz}$ and panel (D): $6 \mathrm{kHz}$. There were no significant differences between the results obtained in the anesthetized animal before and after middle-ear muscles detachment. produced by activation of the middle-ear reflex that also reduces cochlear sensitivity. Several facts assure us that the CAPamplitude reductions observed in these experiments were due to activation of the MOC system and not the middle-ear reflex. First, all contralateral suppressions (other than those in CAP inputoutput curves) were measured at or below $70 \mathrm{~dB}$ SPL intensity 


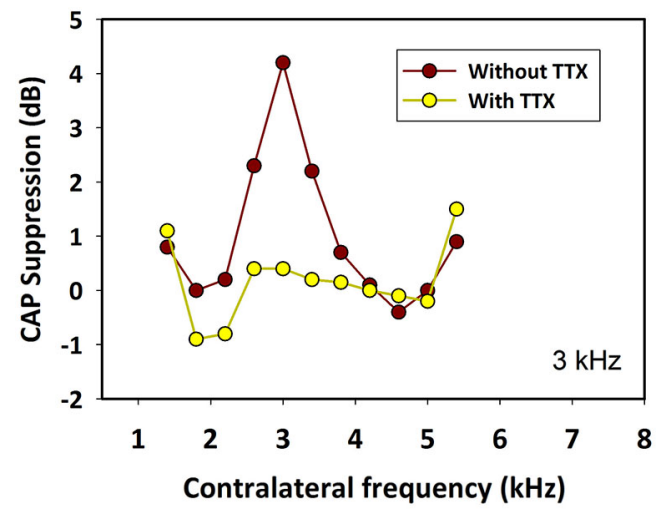

FIGURE 12 | Effect of tetrodotoxin (TTX) in the contralateral cochlea Ipsilateral CAP-reduction tuning curves before (brown) and after (yellow) injection of tetrodotoxin into the contralateral cochlea. The toxin abolished contralateral neural responses and their suppressive effect on ipsilateral CAPs. Ipsilateral tones at $3 \mathrm{kHz}$ and $50 \mathrm{~dB}$ SPL. Contralateral tones at $70 \mathrm{~dB}$ SPL.

levels, and the strongest suppression effects were always found at much lower levels. Second, no differences in contralateral CAP reduction were found in one control animal in which the CAP-suppression frequency tuning was measured before and after middle-ear muscle section (Figure 11). Third, in the three awake chinchillas in which we did find efferent effects on CMs, contralateral sounds produced CAP reductions concomitant with $\mathrm{CM}$ enhancements. The presence of these opposite effects of contralateral stimulation on CAP and CM potentials is strong evidence that they were not produced by middle-ear reflex activation (Guinan, 1996; Robles and Delano, 2008). Fourth, the fact that CAP suppressions produced by contralateral tones were always sharply tuned to frequencies equal or close to that of the ipsilateral tone discards any possibility that they could be a consequence of middle-ear reflex activation.

In conclusion, we have shown that: (1) In spite of the lower percentage of uncrossed MOC fibers present in chinchilla, contralateral sounds produce consistent CAP amplitude reductions for $1-6 \mathrm{kHz}$ ipsilateral frequencies. (2) The contralateral tones producing the CAP suppression are frequency tuned to a frequency equal or close to that of the ipsilateral tone. (3) The contralateral produced CAP suppressions correspond to a span of uncrossed MOC fiber innervation reaching at least the central third of the chinchilla cochlea. (4) The contralateral CAP suppression is consistently higher in awake than in anesthetized condition.

\section{ACKNOWLEDGMENTS}

Supported by Fondecyt 1120256 and Fundación Guillermo Puelma.

\section{REFERENCES}

Azeredo, W. J., Kliment, M. L., Morley, B. J., Relkin, E., Slepecky, N. B., Sterns, A., et al. (1999). Olivocochlear neurons in the chinchilla: a retrograde fluorescent labelling study. Hear. Res. 134, 57-70. doi: 10.1016/s0378-5955(99)00069-6

Bowen, M., Aedo, C., León, A., Dragicevic, C. D., Terreros, G., Robles, L., et al. (2014). "Awake state and auditory cortex microstimulation enhance contralateral-noise suppression of cochlear responses in chinchillas," in 37th Annual MidWinter Meeting of the Association for Research in Otolaryngology. Abstract Book, 37:52.

Boyev, K. P., Liberman, M. C., and Brown, M. C. (2002). Effects of anesthesia on efferent-mediated adaptation of the DPOAE. J. Assoc. Res. Otolaryngol. 3, 362-373. doi: 10.1007/s101620020044

Brown, M. C. (1987). Morphology of labeled efferent fibers in the guinea pig cochlea. J. Comp. Neurol. 260, 605-618. doi: 10.1002/cne.902600412

Buño, W. Jr. (1978). Auditory nerve fiber activity influenced by contralateral ear sound stimulation. Exp. Neurol. 59, 62-74. doi: 10.1016/0014-4886(78)90201-7

Chambers, A. R., Hancock, K. E., Maison, S. F., Liberman, M. C., and Polley, D. B. (2012). Sound-evoked olivocochlear activation in unanesthetized mice. J. Assoc. Res. Otolaryngol. 13, 209-217. doi: 10.1007/s10162-011-0306-Z

Cooper, N. P., and Guinan, J. J. (2003). Separate mechanical processes underlie fast and slow effects of medial olivocochlear efferent activity. J. Physiol. 548, 307-312. doi: 10.1111/j.1469-7793.2003.00307.x

Darrow, K. N., Maison, S. F., and Liberman, M. C. (2006). Cochlear efferent feedback balances interaural sensitivity. Nat. Neurosci. 9, 1474-1476. doi: 10. 1038/nn 1807

Delano, P. H., Elgueda, D., Hamame, C. M., and Robles, L. (2007). Selective attention to visual stimuli reduces cochlear sensitivity in chinchillas. J. Neurosci. 27, 4146-4153. doi: 10.1523/jneurosci.3702-06.2007

Desmedt, J. E. (1962). Auditory-evoked potentials from cochlea to cortex as influenced by activation of the efferent olivocochlear bundle. J. Acoust. Soc. Am. 34, 1478-1496. doi: 10.1121/1.1918374

Desmedt, J. E., and Monaco, P. (1961). Mode of action of the efferent olivocochlear bundle on the inner ear. Nature 192, 1263-1265. doi: 10.1038/1921263a0

de Venecia, R. K., Liberman, M. C., Guinan, J. J., and Brown, M. C. (2005). Medial olivocochlear reflex interneurons are located in the posteroventral cochlear nucleus: a kainic acid lesion study in guinea pigs. J. Comp. Neurol. 487, 345-360. doi: 10.1002/cne.20550

Elgueda, D., Delano, P. H., and Robles, L. (2011). Effects of electrical stimulation of olivocochlear fibers in cochlear potentials in the chinchilla. J. Assoc. Res. Otolaryngol. 12, 317-327. doi: 10.1007/s10162-011-0260-9

Fex, J. (1959). Augmentation of cochlear microphonic by stimulation of efferent fibres to the cochlea; preliminary report. Acta Otolaryngol. 50, 540-541. doi: 10. 3109/00016485909129230

Galambos, R. (1956). Suppression of auditory activity by stimulation of efferent fibers to the cochlea. J. Neurophysiol. 19, 424-437.

Gifford, M. L., and Guinan, J. J. Jr. (1987). Effects of electrical stimulation of medial olivocochlear neurons on ipsilateral and contralateral cochlear responses. Hear. Res. 29, 179-194. doi: 10.1016/0378-5955(87)90166-3

Greenwood, D. D. (1990). A cochlear frequency-position function for several species-29 years later. J. Acoust. Soc. Am. 87, 2592-2605. doi: 10.1121/1. 399052

Guinan, J. J. Jr. (1996). “The physiology of olivocochlear efferents," in The Cochlea, eds P. J. Dallos, A. N. Popper and R. R. Fay (New York: Springer-Verlag), 435-502.

Guinan, J. J. Jr. (2006). Olivocochlear efferents: anatomy, physiology, function and the measurement of efferent effects in humans. Ear Hear. 27, 589-607. doi: 10. 1097/01.aud.0000240507.83072.e7

Guitton, M. J., Avan, P., Puel, J. L., and Bonfils, P. (2004). Medial olivocochlear efferent activity in awake guinea pigs. Neuroreport 15, 1379-1382. doi: 10. 1097/01.wnr.0000131672.15566.64

Harrison, R. V., Sharma, A., Brown, T., Jiwani, S., and James, A. L. (2008). Amplitude modulation of DPOAEs by acoustic stimulation of the contralateral ear. Acta Otolaryngol. 128, 404-407. doi: 10.1080/00016480701784965

Iurato, S., Smith, C. A., Eldredge, D. H., Henderson, D., Carr, C., Ueno, Y., et al. (1978). Distribution of the crossed olivocochlear bundle in the chinchilla's cochlea. J. Comp. Neurol. 182, 57-76. doi: 10.1002/cne.901820105

James, A. L., Harrison, R. V., Pienkoesky, M., Dajani, H. R., and Mount, R. J. (2005). Dynamics of the real time DPOAE contralateral suppression in chinchillas and humans. Int. J. Audiol. 44, 118-129. doi: 10.1080/14992020400029996

Kawase, T., Delgutte, B., and Liberman, M. C. (1993). Antimasking effects of the olivocochlear reflex: II. Enhancement of auditory-nerve response to masked tones. J. Neurophysiol. 70, 2533-2549.

Larsen, E., and Liberman, M. C. (2009). Slow build-up of cochlear suppression during sustained contralateral noise: central modulation of olivocochlear efferents? Hear. Res. 256, 1-10. doi: 10.1016/j.heares.2009.02.002 
León, A., Elgueda, D., Silva, M. A., Hamamé, C. M., and Delano, P. H. (2012). Auditory cortex basal activity modulates cochlear responses in chinchillas. PLoS One 7:e36203. doi: 10.1371/journal.pone.0036203

Liberman, M. C. (1989). Rapid assessment of sound-evoked olivocochlear feedback: suppression of compound action potential by contralateral sound. Hear. Res. 38, 47-56. doi: 10.1016/0378-5955(89)90127-5

Liberman, M. C., and Brown, M. C. (1986). Physiology and anatomy of single olivocochlear neurons in the cat. Hear. Res. 24, 17-36. doi: 10.1016/03785955(86)90003-1

Lilaonitkul, W., and Guinan, J. J. Jr. (2009). Human medial olivocochlear reflex: effects as functions of contralateral, ipsilateral and bilateral elicitor bandwidths. J. Assoc. Res. Otolaryngol. 10, 459-470. doi: 10.1007/s10162-009-0163-1

Müller, M., Hoidis, S., and Smolders, J. W. (2010). A physiological frequencyposition map of the chinchilla cochlea. Hear. Res. 268, 184-193. doi: 10.1016/j. heares.2010.05.021

Popelár, J., Erre, J. P., Syka, J., and Aran, J. M. (2001). Effects of contralateral acoustical stimulation on three measures of cochlear function in the guinea pig. Hear. Res. 152, 128-138. doi: 10.1016/s0378-5955(00)00244-6

Puel, J. L., and Rebillard, G. (1990). Effect of contralateral sound stimulation on the distortion product 2F1-F2: evidence that the medial efferent system is involved. J. Acoust. Soc. Am. 87, 1630-1635. doi: 10.1121/1.399410

Puria, S., Guinan, J. J. Jr., and Liberman, M. C. (1996). Olivocochlear reflex assays: effects of contralateral sound on compound action potentials versus ear-canal distortion products. J. Acoust. Soc. Am. 99, 500-507. doi: 10.1121/1. 414508

Rajan, R. (1995). Frequency and loss dependence of the protective effects of the olivocochlear pathways in cats. J. Neurophysiol. 74, 598-615.

Robertson, D. (1984). Horseradish peroxidase injection of physiologically characterized afferent and efferent neurons in the guinea pig spiral ganglion. Hear. Res. 15, 113-121. doi: 10.1016/0378-5955(84)90042-x

Robertson, D., and Gummer, M. (1985). Physiological and morphological characterization of efferent neurons in the guinea pig cochlea. Hear. Res. 20, 63-77. doi: 10.1016/0378-5955(85)90059-0

Robles, L., and Delano, P. H. (2008). "Efferent system," in Handbook of The Senses, Audition, eds P. Dallos and D. Oertel (San Diego: Academic Press), 413-445.

Sridhar, T. S., Liberman, M. C., Brown, M. C., and Sewell, W. F. (1995). A novel cholinergic "slow effect" of efferent stimulation on cochlear potentials in the guinea pig. J. Neurosci. 15, 3667-3678.

Velluti, R. A. (1997). Interactions between sleep and sensory physiology. J. Sleep Res. 6, 61-77. doi: 10.1046/j.1365-2869.1997.00031.x
Vetter, D. E., Saldaña, E., and Mugnaini, E. (1993). Input from the inferior colliculus to medial olivocochlear neurons in the rat: a double label study with PHA-L and cholera toxin. Hear. Res. 70, 173-186. doi: 10.1016/0378-5955(93) 90156-u

Warr, W. B., and Guinan, J. J. Jr. (1979). Efferent innervation of the organ of Corti: two separate systems. Brain Res. 173, 152-155. doi: 10.1016/00068993(79)91104-1

Warren, E. H., and Liberman, M. C. (1989a). Effects of contralateral sound on auditory-nerve responses. I. Contributions of cochlear efferents. Hear. Res. 37, 89-104. doi: 10.1016/0378-5955(89)90032-4

Warren, E. H., and Liberman, M. C. (1989b). Effects of contralateral sound on auditory-nerve responses. II. Dependence on stimulus variables. Hear. Res. 37, 105-121. doi: 10.1016/0378-5955(89)90033-6

Winer, J. A., and Prieto, J. J. (2001). Layer V in cat primary auditory cortex (AI): cellular architecture and identification of projection neurons. J. Comp. Neurol. 434, 379-412. doi: 10.1002/cne.1183

Wolter, N. E., Harrison, R. V., and James, A. L. (2014). Separating the contributions of olivocochlear and middle ear muscle reflexes in modulation of distortion product otoacoustic emission levels. Audiol. Neurotol. 19, 41-48. doi: 10. $1159 / 000356174$

Zhao, W., and Dhar, S. (2012). Frequency tuning of the contralateral medial olivocochlear reflex in humans. J. Neurophysiol. 108, 25-30. doi: 10.1152/jn. 00051.2012

Conflict of Interest Statement: The authors declare that the research was conducted in the absence of any commercial or financial relationships that could be construed as a potential conflict of interest.

Received: 08 November 2014; accepted: 08 February 2015; published online: 02 March 2015.

Citation: Aedo C, Tapia E, Pavez E, Elgueda D, Delano PH and Robles L (2015) Stronger efferent suppression of cochlear neural potentials by contralateral acoustic stimulation in awake than in anesthetized chinchilla. Front. Syst. Neurosci. 9:21. doi: $10.3389 /$ fnsys.2015.00021

This article was submitted to the journal Frontiers in Systems Neuroscience.

Copyright (C) 2015 Aedo, Tapia, Pavez, Elgueda, Delano and Robles. This is an openaccess article distributed under the terms of the Creative Commons Attribution License (CC BY). The use, distribution and reproduction in other forums is permitted, provided the original author(s) or licensor are credited and that the original publication in this journal is cited, in accordance with accepted academic practice. No use, distribution or reproduction is permitted which does not comply with these terms. 